\title{
Application of traction-method to hybrid endoscopic submucosal dissection for gastrointestinal tumors
}

Hybrid endoscopic submucosal dissection (ESD) is a simplified endoscopic treatment for conventional ESD that consists of snaring of submucosal layer after completion of circumferential mucosal incision and subsequent partial submucosal dissection [1] Previous studies have revealed that hybrid ESD reduces the en bloc resection rate although it significantly shortens the treatment procedure time [2,3]. To improve the en bloc resection rate, we proposed a traction-assisted hybrid ESD using the clip-with-thread technique and a multi-functional snare, SOUTEN (Kaneka Medix, Tokyo, Japan), in the porcine stomach model [4].

A 20-mm mock lesion was prepared at the greater curvature of the gastric body. Hyaluronic acid was injected into the submucosal layer around the lesion using an injection needle. Then, circumferential mucosal incision and partial submucosal dissection were performed using the distal tip of the SOUTEN. Subsequently, a clip with thread was placed on the proximal mucosal flap of the lesion ( $\mathbf{F i g . 1} \mathbf{a}$ ). The thread was passed through a ring of the snare being inserted through a biopsy channel ( Fig.1 b). After insertion of the endoscope, the loosened thread was straightened ( $\triangleright$ Fig. $1 \mathbf{c}, \mathbf{d}$ ). The distal tip of the snare was placed at the distal edge of the lesion. With the snare open, the clipwith-thread was pulled until the lesion was lifted high enough to conduct snaring under direct vision of the submucosal layer ( $\downarrow$ Video 1 ). En bloc resection of the lesion was achieved by snaring without any fault.

Traction-assisted hybrid ESD can be performed using a standard single-channel endoscope to achieve en bloc resection of gastrointestinal tract tumors. The application of the traction method could expand the indication for hybrid ESD of larger lesions.

Endoscopy_UCTN_Code_TTT_1AO_2AC

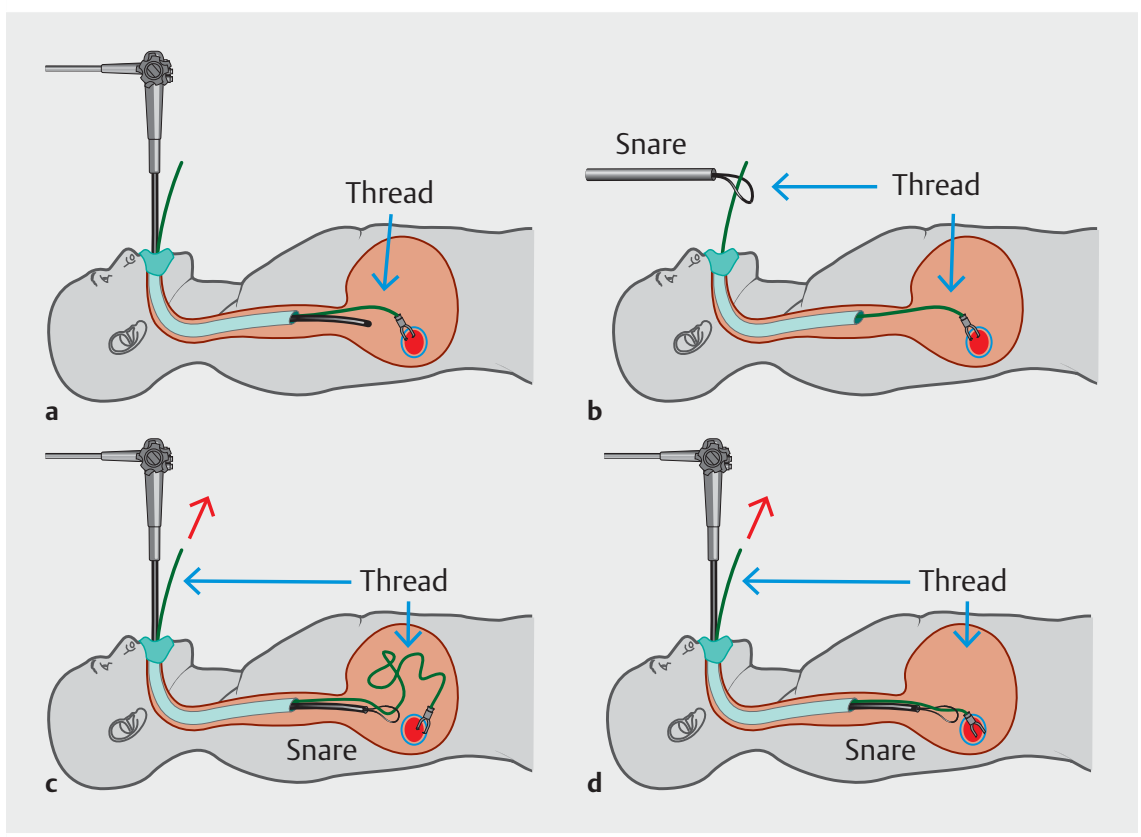

Fig. 1 The schemas showing the step-by-step procedure for traction-assisted hybrid endoscopic submucosal dissection. a A clip-with-thread was placed near the proximal part of the lesion. $\mathbf{b} A$ thread was passed through a ring of the snare being inserted through a biopsy channel. c A standard single-channel endoscope was inserted into the stomach. d The loosened thread was straightened.

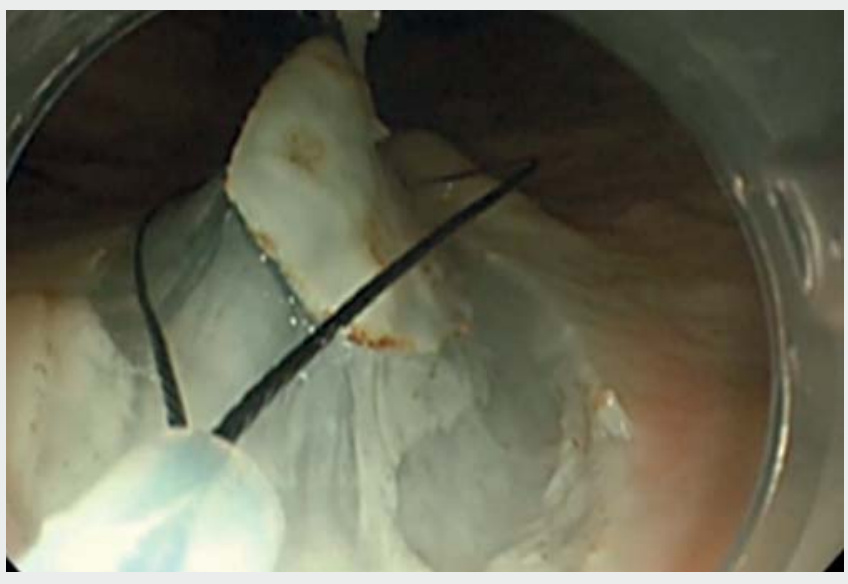

Video 1 Traction-assisted hybrid endoscopic submucosal dissection. 
Eikichi thara participated in the funded research of Takeda Pharmaceutical Co., Ltd. and belongs to the endowed course supported by the companies mentioned, including Ono Pharmaceutical Co., Ltd., Miyarisan Pharmaceutical Co. Ltd., Sanwa Kagaku Kenkyusho Co., Ltd., Otsuka Pharmaceutical Factory, Inc., Fujifilm Medical Co., Ltd., Termo Corporation, Fancl Corporation, and Ohga Pharmacy. Eikichi Ihara received a lecture fee from Takeda Pharmaceutical Co.

The authors

Mitsuru Esaki ${ }^{1,2}$, Ryosuke Maehara', Shuzaburo Nagatomo', Kei Nishioka', Yosuke Minoda ${ }^{1}$, Haruei Ogino' ${ }^{1}$ Eikichi Ihara', 3

1 Department of Medicine and Bioregulatory Science, Graduate School of Medical Sciences, Kyushu University, Fukuoka, Japan

2 Division of Gastroenterology and Hepatology, Department of Medicine, Nihon University School of Medicine, Tokyo, Japan

3 Department of Gastroenterology and Metabolism, Graduate School of Medical Sciences, Kyushu University, Fukuoka, Japan

\section{Mitsuru Esaki, MD}

Department of Medicine and Bioregulatory Science, Graduate School of Medical

Sciences, Kyushu University, 3-1-1, Maidashi, Higashi-ku, 812-8582, Fukuoka, Japan Fax: +81-92-642-5286

esaki_saiseikai@yahoo.co.jp

\section{References}

[1] Esaki M, Suzuki S, Horii T et al. Reduction in the procedure time of hybrid endoscopic submucosal dissection for early gastric neoplasms: a multi-center retrospective propensity score-matched analysis. Therap Adv Gastroenterol 2020; 13 : 1756284820939420

[2] McCarty TR, Bazarbashi AN, Thompson CC et al. Hybrid endoscopic submucosal dissection (ESD) compared with conventional ESD for colorectal lesions: a systematic review and meta-analysis. Endoscopy 2020. doi:10.1055/a-1266-1855

[3] Fuccio L, Hassan C, Ponchon T et al. Clinical outcomes after endoscopic submucosal dissection for colorectal neoplasia: a systematic review and meta-analysis. Gastrointest Endosc 2017; 86: 74-86.e17

[4] Ohata K, Muramoto T, Minato Y et al. Usefulness of a multifunctional snare designed for colorectal hybrid endoscopic submucosal dissection (with video). Endosc Int Open 2018: 6: E249-E253
Bibliography

Endoscopy 2022; 54: E160-E161

DOI 10.1055/a-1422-2902

ISSN 0013-726X

published online 20.4.2021

(c) 2021. Thieme. All rights reserved.

Georg Thieme Verlag KG, Rüdigerstraße 14 , 70469 Stuttgart, Germany

\section{ENDOSCOPY E-VIDEOS}

https://eref.thieme.de/e-videos

回屌 Endoscopy E-Videos is an open access online section, 自嗮: reporting on interesting cases and new techniques in gastroenterological endoscopy. All papers include a high quality video and all contributions are freely accessible online. Processing charges apply (currently EUR 375), discounts and wavers acc. to HINARI are available.

This section has its own submission website at https://mc.manuscriptcentral.com/e-videos 